Article

\title{
Evaluation of Mycotoxin Residues on Ready-to-Eat Food by Chromatographic Methods Coupled to Mass Spectrometry in Tandem
}

\author{
Dionisia Carballo ${ }^{1}$, Guillermina Font ${ }^{2}$, Emilia Ferrer ${ }^{2}$ and Houda Berrada ${ }^{2, *}$ (1) \\ 1 Faculty of Agricultural Science, National University of Asunción, San Lorenzo 2160, Paraguay; \\ diocarve@alumni.uv.es \\ 2 Laboratory of Food Chemistry and Toxicology, Faculty of Pharmacy, University of Valencia, Avenue Vicent \\ Andrés Estellés s/n, 46100 Burjassot, Spain; Guillermina.font@uv.es (G.F.); Emilia.ferrer@uv.es (E.F.) \\ * Correspondence: houda.berrada@uv.es; Tel.: +34-963-544-117
}

Received: 4 May 2018; Accepted: 13 June 2018; Published: 15 June 2018

\begin{abstract}
Simultaneous determination of twenty-seven mycotoxins in ready-to-eat food samples using "Quick Easy Cheap Rough and Safe" (QuEChERS) extraction and chromatographic methods coupled to mass spectrometry in tandem is described in this study. Mycotoxins included in this survey were aflatoxins $\left(B_{1}, B_{2}, G_{1}, G_{2}\right)$, enniatins $\left(A, A_{1}, B, B_{1}\right)$, beauvericin (BEA), fumonisins $\left(\mathrm{FB}_{1}, \mathrm{FB}_{2}\right)$, sterigmatocystin (STG), deoxynivalenol (DON), 3-acetyl-deoxynivalenol (3-ADON), 15-acetyl-deoxynivalenol (15-ADON), nivalenol (NIV), neosolaniol (NEO), diacetoxyscirpenol (DAS), fusarenon-X (FUS-X), zearalenone (ZEA), $\alpha$-zearalanol ( $\alpha Z \mathrm{ZAL}), \beta$-zearalenone ( $\beta Z \mathrm{ZAL}), \alpha$-zearalenol $(\alpha Z O L), \beta$-zearalenol ( $\beta z o l), T 2$, and HT-2 toxin. The method showed satisfactory extraction results with recoveries ranging from 63 to $119 \%$ for the different food matrix samples. Limits of detection (LODS) and quantification (LOQs) were between $0.15-1.5 \mu \mathrm{g} / \mathrm{kg}$ and $0.5-5 \mu \mathrm{g} / \mathrm{kg}$, respectively. The method was successfully applied to the analysis of 25 ready-to-eat food samples. Results showed presence of deoxynivalenol at $36 \%$ of samples $(2.61-21.59 \mu \mathrm{g} / \mathrm{kg})$, enniatin $\mathrm{B}$ at $20 \%$ of samples $(9.83-86.32 \mu \mathrm{g} / \mathrm{kg})$, HT-2 toxin at $16 \%$ of samples $(9.06-34.43 \mu \mathrm{g} / \mathrm{kg})$, and aflatoxin $\mathrm{G}_{2}$ at $4 \%$ of samples $(2.84 \mu \mathrm{g} / \mathrm{kg})$. Mycotoxins were detected mainly in ready-to-eat food samples prepared with cereals, vegetables, and legumes, even at levels below those often obtained from raw food.
\end{abstract}

Keywords: mycotoxins; ready-to-eat food; GC-MS/MS; LC-MS/MS; Valencia

Key Contribution: An analytical method based on QuEChERS extraction was developed to evaluate the presence of twenty-seven mycotoxins in ready-to-eat food by chromatographic methods coupled to mass spectrometry in tandem.

\section{Introduction}

Mycotoxins are a group of toxic compounds produced as secondary metabolites by certain fungi of the genus Aspergillus, Penicillium, Fusarium, Alternaria, and Claviceps that grow under different climate conditions and have been reported in several food matrices like cereals, peanuts, meat, eggs, milk, and fruits [1,2]. Chronic exposure to some mycotoxins can produce carcinogenic, mutagenic, or teratogenic effects. Aflatoxins (AFs) are indicated as carcinogenic and hepatotoxic and fumonisins (FBs) and ochratoxin A (OTA) are possibly teratogenic, hepatotoxic, and nephrotoxic while patulin (PAT), zearalenone (ZEA), deoxynivalenol (DON), nivalenol (NIV), T-2, and HT-2 toxins are related to toxicological effects mainly on gastrointestinal tract, immune, and endocrine systems [3]. Emerging mycotoxins, such as enniatins ENs and beauvericin, are cytotoxic [4] and their potent cytotoxic activity 
was demonstrated in several mammalian cell lines [5], turning it in a topic for human health [6]. The European Union through Regulation (EC) 1881/2006 set maximum limits in foodstuffs susceptible to mycotoxins contamination to control their quality and safety [7] (Table 1).

Table 1. Summary of maximum levels of some mycotoxin in foodstuffs.

\begin{tabular}{|c|c|c|}
\hline Mycotoxin & Food Product & $\begin{array}{c}\text { Maximum } \\
\text { Levels }(\mu \mathrm{g} / \mathrm{kg})\end{array}$ \\
\hline $\mathrm{AFB}_{1}$ & $\begin{array}{l}\text { Processed cereal-based foods and baby foods for infants and young } \\
\text { children, dietetic food destined for physical treatment, cereals and cereal } \\
\text { products, dried fruit, groundnuts and nuts, and spices }\end{array}$ & $0.1-8.0$ \\
\hline Sum of AFs & Cereal and cereal-based products, dried fruit, coffee, groundnuts, and nuts & $4.0-15.0$ \\
\hline OTA & $\begin{array}{l}\text { Processed cereal-based foods and baby foods for infants and young } \\
\text { children, dietetic food destined for physical treatment, cereals and cereal } \\
\text { products, dried vine fruit, wine, coffee, grape juice }\end{array}$ & $0.5-10$ \\
\hline DON & $\begin{array}{l}\text { Processed cereal-based products and baby foods for infants and young } \\
\text { children, cereals intended for direct human consumption, cereal flour, } \\
\text { bran and germ as end product marketed for direct human consumption, } \\
\text { pasta dry, bread, pastries, biscuits, cereal snacks, and breakfast cereals }\end{array}$ & $200-750$ \\
\hline ZEA & $\begin{array}{l}\text { Processed maize-based products and baby foods for infants and young } \\
\text { children, maize and maize-based products, bread, and other } \\
\text { unprocessed cereal }\end{array}$ & 20-200 \\
\hline Sum of FBs & $\begin{array}{l}\text { Processed maize-based products and baby foods for infants and young } \\
\text { children, maize-based products, and unprocessed maize }\end{array}$ & 200-2000 \\
\hline
\end{tabular}

$\mathrm{AFB}_{1}$; Aflatoxin $\mathrm{B}_{1}$; AFs: Aflatoxins; OTA: ochratoxin A; DON: deoxynivalenol; ZEA: zearalenone; FBs: fumonisins.

The determination of mycotoxins has been highly reported in different food matrices such as cereal products [8], coffee [9], tomatoes and tomato products [10], fruits, vegetables, and legumes [11]. There are several food processing methods that may modify mycotoxin stability [12]. Visconti et al. [13] and Serrano et al. [14] reported gradual reduction of DON and ENs contents in pasta and AFs and OTA decreased in cooked rice through thermal treatments [15].

However, there is limited information on the presence of mycotoxins in ready-to-eat food. Recently, the EFSA (European Food Safety Authority) Panel on Contaminants in the food Chain (CONTAM) emitted a Scientific Opinion recommending that further studies should be conducted on the fate of mycotoxins during the preparation of grain-based products, specially focused in bread, pasta, and fine bakery wares [16].

Chromatographic methods coupled to mass spectrometry are the techniques often used for the determination of mycotoxins in food matrices $[17,18]$. One of the main objectives pursued in most laboratories is the application of multiple analyte determination with minimal sample treatment. To achieve increased throughput over traditional mycotoxin extraction methods, novel techniques were employed and by using appropriate mixtures of extraction and disperser solvents in dispersive liquid-liquid microextraction (DLLME), and also by adding inorganic salt into a mixture of water and organic solvent in salting-out liquid-liquid extraction (SALLE).

The "Quick Easy Cheap Rough and Safe" (QuEChERS) extraction, originally developed by Anastassiades et al. [19], based on acetonitrile extraction followed by a salting-out and quick dispersive solid-phase extraction (d-SPE), takes advantage of the electric charge of target compounds to allow their extraction with small amounts of non-chlorinated organic solvents. It is also pointed out as a fast and economical mycotoxin extraction method from various processed cereal-based foods [20].

To the best of our knowledge, scarce data exist in the literature concerning mycotoxin level in ready-to-eat food, and in this sense, the development of a simple and efficient method to assess human mycotoxin exposure via ready-to-eat food analysis is necessary. 
In the present investigation, an analytical method based on QuEChERS extraction was used to evaluate the presence of twenty-seven mycotoxins $\mathrm{AFB}_{1}, \mathrm{AFB}_{2}, \mathrm{AFG}_{1}, \mathrm{AFG}_{2}, \mathrm{OTA}, \mathrm{FB}_{1}, \mathrm{FB}_{2}$, ENA, $\mathrm{ENA}_{1}, \mathrm{ENB}, \mathrm{ENB}_{1}, \mathrm{BEA}, \mathrm{STG}, \mathrm{ZON}, \alpha-\mathrm{ZAL}, \beta-\mathrm{ZAL}, \alpha-\mathrm{ZOL}, \beta-\mathrm{ZOL}, \mathrm{DON}, 3-\mathrm{ADON}, 15-\mathrm{ADON}, \mathrm{DAS}$, NIV, FUS-X, NEO, T-2, and HT-2 in ready-to-eat food by LC-MS/MS and GC-MS/MS.

\section{Results}

\subsection{Analytical Method Validation}

The parameters considered for validation purposes were instrumental linearity, matrix effect, sensitivity (LOD and LOQ), and accuracy according to the EU Commission Decision 2002/657 EC [21]. The criteria for confirmation of positive findings was to fulfil retention time agreement and peak areas ratio obtained from reference standard quantification $(\mathrm{Q})$ and qualification $(\mathrm{q})$ transitions (Table 2).

All mycotoxins exhibited good linearity over the working range (LOQ and 100 $\times$ LOQ). The regression coefficients of all calibration curves were $\left(\mathrm{r}^{2}\right)$ higher than 0.996 , demonstrating a good linearity.

Satisfactory results in terms of recoveries were found for all mycotoxins studied at three fortification levels $(25,50,100 \mu \mathrm{g} / \mathrm{kg})$. The range of recovery values for the three concentrations tested in the five food groups studied was between $63 \%$ and $119 \%$.

The LODs and LOQs obtained were from 0.15 to $5 \mu \mathrm{g} / \mathrm{kg}$ for all mycotoxins analyzed (Table 2). As can be observed, ENs reached very good sensitivity by LC-MS/MS and DON by GC-MS/MS, achieving LOQs $0.15-0.5 \mu \mathrm{g} / \mathrm{kg}$, respectively.

The matrix effect (signal enhancement or suppression) was investigated by calculating the percentage ratio between the slopes of the matrix-matched calibration curve and the curve in solvent.

The matrix effect parameter (ME) behavior in the different studied matrix is shown in Table 2. The majority of the analytes showed a signal enhancement, especially trichothecenes (ZON, 3-ADON and NEO) in fish composite with ME of $158 \%, 173 \%$, and $175 \%$, respectively. On the other hand, signal suppression was registered for AFG1, AFG2, and FB2 in legumes composite with ME values of 53\%, $58 \%$, and $59 \%$, respectively. A similar value was obtained for BEA in meat composite with ME of $58 \%$. The matrix-matched standards were used for effective qualifications taking into account results of suppression and enhancement of the signal. 
Table 2. Analytical performance of the proposed method: mass spectrometry transitions, LOD, LOQ, ME, and recovery range for the different food matrices studied.

\begin{tabular}{|c|c|c|c|c|c|c|c|c|c|c|c|c|c|c|}
\hline \multirow{3}{*}{ Mycotoxin } & \multicolumn{2}{|c|}{ Transitions } & \multicolumn{2}{|c|}{ Cereals } & \multicolumn{2}{|c|}{ Legumes } & \multicolumn{2}{|c|}{ Fish } & \multicolumn{2}{|c|}{ Vegetables } & \multicolumn{2}{|c|}{ Meats } & \multirow{3}{*}{$\begin{array}{c}\text { ME } \\
(\%)\end{array}$} & \multirow{3}{*}{$\begin{array}{c}\text { Recovery } \\
(\%)\end{array}$} \\
\hline & Quantitative & Qualitative & LOD & LOQ & LOD & LOQ & LOD & LOQ & LOD & LOQ & LOD & LOQ & & \\
\hline & $\mathbf{Q}$ & $\mathbf{Q}$ & $\mu \mathrm{g} / \mathrm{kg}$ & $\mu \mathrm{g} / \mathrm{kg}$ & $\mu \mathrm{g} / \mathrm{kg}$ & $\mu \mathrm{g} / \mathrm{kg}$ & $\mu \mathrm{g} / \mathrm{kg}$ & $\mu \mathrm{g} / \mathrm{kg}$ & $\mu \mathrm{g} / \mathrm{kg}$ & $\mu \mathrm{g} / \mathrm{kg}$ & $\mu \mathrm{g} / \mathrm{kg}$ & $\mu \mathrm{g} / \mathrm{kg}$ & & \\
\hline OTA & $404>102^{a}$ & $404>239$ & 1.5 & 5 & 1.5 & 5 & 1.5 & 5 & 1.5 & 5 & 1.5 & 5 & $73-121$ & $71-91$ \\
\hline $\mathrm{AFB}_{1}$ & $313>241^{a}$ & $313>289$ & 0.15 & 0.5 & 0.15 & 0.5 & 0.15 & 0.5 & 0.15 & 0.5 & 0.3 & 1 & 65-106 & $67-98$ \\
\hline AFB2 & $315>286^{a}$ & $315>259$ & 0.3 & 1 & 0.3 & 1 & 0.3 & 1 & 0.3 & 1 & 0.3 & 1 & $63-77$ & 67-116 \\
\hline $\mathrm{AFG}_{1}$ & $329>243^{a}$ & $329>311$ & 0.3 & 1 & 1.5 & 5 & 0.3 & 1 & 0.3 & 1 & 0.15 & 0.5 & $58-117$ & 79-102 \\
\hline $\mathrm{AFG}_{2}$ & $331>313^{a}$ & $331>245$ & 0.15 & 0.5 & 0.3 & 1 & 0.3 & 1 & 0.3 & 1 & 0.3 & 1 & $58-97$ & $67-90$ \\
\hline $\mathrm{FB}_{1}$ & $722>334^{a}$ & $722>352$ & 1.5 & 5 & 1.5 & 5 & 1.5 & 5 & 0.3 & 1 & 1.5 & 5 & 61-141 & 69-114 \\
\hline $\mathrm{FB}_{2}$ & $706>336^{a}$ & $706>318$ & 1.5 & 5 & 1.5 & 5 & 1.5 & 5 & 0.3 & 1 & 1.5 & 5 & 59-102 & $65-116$ \\
\hline ENA & $699>228^{a}$ & $699>210$ & 0.15 & 0.5 & 0.3 & 0.5 & 0.3 & 1 & 0.15 & 0.5 & 0.15 & 0.5 & $65-117$ & 74-114 \\
\hline $\mathrm{ENA}_{1}$ & $685>214^{a}$ & $685>210$ & 0.15 & 0.5 & 0.15 & 0.5 & 0.15 & 0.5 & 0.15 & 0.5 & 0.15 & 0.5 & $91-125$ & 62-104 \\
\hline ENB & $657>196^{a}$ & $657>214$ & 0.15 & 0.5 & 0.3 & 1 & 0.15 & 0.5 & 0.15 & 0.5 & 0.3 & 1 & 68-101 & 69-111 \\
\hline $\mathrm{ENB}_{1}$ & $671>214^{a}$ & $671>228$ & 0.15 & 0.5 & 0.15 & 0.5 & 0.15 & 0.5 & 0.15 & 0.5 & 0.15 & 0.5 & $74-96$ & 69-119 \\
\hline BEA & $801>784^{a}$ & $801>244$ & 0.15 & 0.5 & 0.15 & 0.5 & 0.15 & 0.5 & 0.15 & 0.5 & 0.3 & 1 & 58-103 & 78-99 \\
\hline STG & $325>281^{a}$ & $325>310$ & 1.5 & 5 & 1.5 & 5 & 0.3 & 1 & 1.5 & 5 & 1.5 & 5 & $70-116$ & 71-102 \\
\hline DON & $392>259^{b}$ & $407>197$ & 0.15 & 0.5 & 0.15 & 0.5 & 0.15 & 0.5 & 0.15 & 0.5 & 0.15 & 0.5 & $82-114$ & $75-107$ \\
\hline 3-ADON & $392>287^{b}$ & $467>147$ & 0.75 & 2.5 & 0.15 & 0.5 & 0.15 & 0.5 & 1.5 & 5 & 0.15 & 0.5 & $78-173$ & 89-117 \\
\hline $15-A D O N$ & $392>217^{b}$ & $392>184$ & 0.75 & 2.5 & 0.15 & 0.5 & 0.15 & 0.5 & 0.15 & 0.5 & 0.15 & 0.5 & $77-148$ & $73-98$ \\
\hline NIV & $289>73^{b}$ & $379>73$ & 1.5 & 5 & 0.75 & 2.5 & 1.5 & 5 & 1.5 & 5 & 0.75 & 2.5 & $82-153$ & $60-79$ \\
\hline NEO & $252>195^{b}$ & $252>167$ & 0.15 & 0.5 & 0.15 & 0.5 & 0.75 & 2.5 & 0.15 & 0.5 & 0.15 & 0.5 & $77-175$ & $91-114$ \\
\hline DAS & $350>229^{b}$ & $378>124$ & 0.75 & 2.5 & 0.75 & 2.5 & 0.75 & 2.5 & 0.75 & 2.5 & 0.15 & 0.5 & 60-144 & 60-102 \\
\hline FUS-X & $450>260^{b}$ & $450>245$ & 0.75 & 2.5 & 0.75 & 2.5 & 0.75 & 2.5 & 1.5 & 5 & 0.15 & 0.5 & $78-151$ & 68-106 \\
\hline $\mathrm{T}-2$ & $350>244^{b}$ & $350>229$ & 0.75 & 2.5 & 0.75 & 2.5 & 0.75 & 2.5 & 0.75 & 2.5 & 0.75 & 2.5 & 96-151 & 73-107 \\
\hline HT-2 & $347>157^{b}$ & $347>185$ & 0.15 & 0.5 & 0.15 & 0.5 & 0.15 & 0.5 & 0.75 & 2.5 & 0.15 & 0.5 & $73-137$ & $73-113$ \\
\hline ZEA & $462>151^{b}$ & $462>333$ & 0.15 & 0.5 & 0.15 & 0.5 & 1.5 & 5 & 0.15 & 0.5 & 1.5 & 5 & 65-158 & 67-104 \\
\hline$\alpha-Z A L$ & $433>309^{b}$ & $433>295$ & 0.15 & 0.5 & 0.15 & 0.5 & 0.75 & 2.5 & 0.15 & 0.5 & 0.15 & 0.5 & 73-155 & 66-117 \\
\hline$\beta-Z A L$ & $307>292^{b}$ & $307>277$ & 0.75 & 2.5 & 1.5 & 5 & 1.5 & 5 & 1.5 & 5 & 1.5 & 5 & $62-132$ & $70-89$ \\
\hline$\alpha-\mathrm{ZOL}$ & $305>289^{b}$ & $305>73$ & 1.5 & 5 & 1.5 & 5 & 1.5 & 5 & 1.5 & 5 & 0.75 & 2.5 & 58-145 & $63-77$ \\
\hline$\beta-\mathrm{ZOL}$ & $536>446^{b}$ & $536>333$ & 0.15 & 0.5 & 1.5 & 5 & 1.5 & 5 & 0.75 & 2.5 & 1.5 & 5 & $71-128$ & $63-79$ \\
\hline
\end{tabular}

${ }^{a}$ LC-MS/MS determination. ${ }^{b}$ GC-MS/MS determination. 


\subsection{Sample Analysis}

Once validated, the method proposed was applied to evaluate the presence of mycotoxins in 25 ready-to-eat food samples. The results obtained are summarized in Table 3.

Table 3. Detected concentrations of DON, ENB, HT-2, and $\mathrm{AFG}_{2}$ in ready-to-eat food samples.

\begin{tabular}{|c|c|c|c|c|}
\hline \multirow{2}{*}{ Samples } & \multicolumn{4}{|c|}{ Concentration $\mu \mathrm{g} / \mathrm{kg}$ RSD (\%) } \\
\hline & DON & ENB & HT-2 & $\mathrm{AFG}_{2}$ \\
\hline \multicolumn{5}{|l|}{ Cereals } \\
\hline Lasagne & $2.84 \pm 2.2$ & $12.25 \pm 3.2$ & $34.43 \pm 0.6$ & n.d. \\
\hline Macaroni & $5.27 \pm 4.2$ & $9.83 \pm 1.0$ & n.d. & n.d. \\
\hline Spaghetti pesto & $21.59 \pm 1.0$ & $11.51 \pm 6.2$ & $7.23 \pm 4.5$ & n.d. \\
\hline Noodles & $4.75 \pm 10.5$ & $86.32 \pm 12.2$ & $18.85 \pm 1.6$ & n.d. \\
\hline Rice (Paella) & n.d. & n.d. & n.d. & 2.84 \\
\hline Rice salad & $2.61 \pm 0.2$ & n.d. & n.d. & n.d. \\
\hline Pizza & $3.39 \pm 4.8$ & n.d. & 9.06 & n.d. \\
\hline Quiche & $4.1 \pm 1.0$ & $14.68 \pm 4.2$ & n.d. & n.d. \\
\hline \multicolumn{5}{|l|}{ Vegetable } \\
\hline Vegetable soup & n.d. & n.d. & n.d. & n.d. \\
\hline Garlic soup & $6.19 \pm 0.2$ & n.d. & n.d. & n.d. \\
\hline Cream of leek & n.d. & n.d. & n.d. & n.d. \\
\hline Gratin broccoli & n.d. & n.d. & n.d. & n.d. \\
\hline Scrambled spinach & n.d. & n.d. & n.d. & n.d. \\
\hline Sauteed artichoke & n.d. & n.d. & n.d. & n.d. \\
\hline \multicolumn{5}{|l|}{ Fish } \\
\hline Grilled salmon & n.d. & n.d. & n.d. & n.d. \\
\hline Grilled tuna & n.d. & n.d. & n.d. & n.d. \\
\hline Baked perch fillets & n.d. & n.d. & n.d. & n.d. \\
\hline Hake in white wine & n.d. & n.d. & n.d. & n.d. \\
\hline Grilled sole & n.d. & n.d. & n.d. & n.d. \\
\hline \multicolumn{5}{|l|}{ Legume } \\
\hline Lentils & n.d. & n.d. & n.d. & n.d. \\
\hline Broad beans & $6.98 \pm 0.2$ & n.d. & n.d. & n.d. \\
\hline Red beans & n.d. & n.d. & n.d. & n.d. \\
\hline Cream of chickpeas & n.d. & n.d. & n.d. & n.d. \\
\hline \multicolumn{5}{|l|}{ Meats } \\
\hline $\begin{array}{l}\text { Grilled chicken } \\
\text { breast }\end{array}$ & n.d. & n.d. & n.d. & n.d. \\
\hline Grilled pork loin & n.d. & n.d. & n.d. & n.d. \\
\hline
\end{tabular}

n.d.: not detected.

Mycotoxins have been detected mainly in food prepared with cereals, vegetables, and legumes. The most prevalent mycotoxin was DON with total incidence of $36 \%$ at concentrations of 2.61-21.59 $\mathrm{\mu g} / \mathrm{kg}$ being present in pasta, quiche, pizza, garlic soup, and broad beans. ENB was detected in pasta and quiche samples with total incidence of $20 \%$ at concentrations of 9.83-86.32 $\mu \mathrm{g} / \mathrm{kg}$. HT-2 toxin was found in pasta and pizza samples with total incidence of $16 \%$ at concentrations of 9.06-34.43 $\mu \mathrm{g} / \mathrm{kg}$. Finally, $\mathrm{AFG}_{2}$ was evidenced at a concentration of $2.84 \mu \mathrm{g} / \mathrm{kg}$ in one sample of rice. Figure 1 shows the chromatogram from a pasta sample $(n=3)$ naturally contaminated by ENB $(86.32 \pm 12.2 \mu \mathrm{g} / \mathrm{kg})$ and DON $(21.59 \pm 6.2 \mu \mathrm{g} / \mathrm{kg})$. 
A)

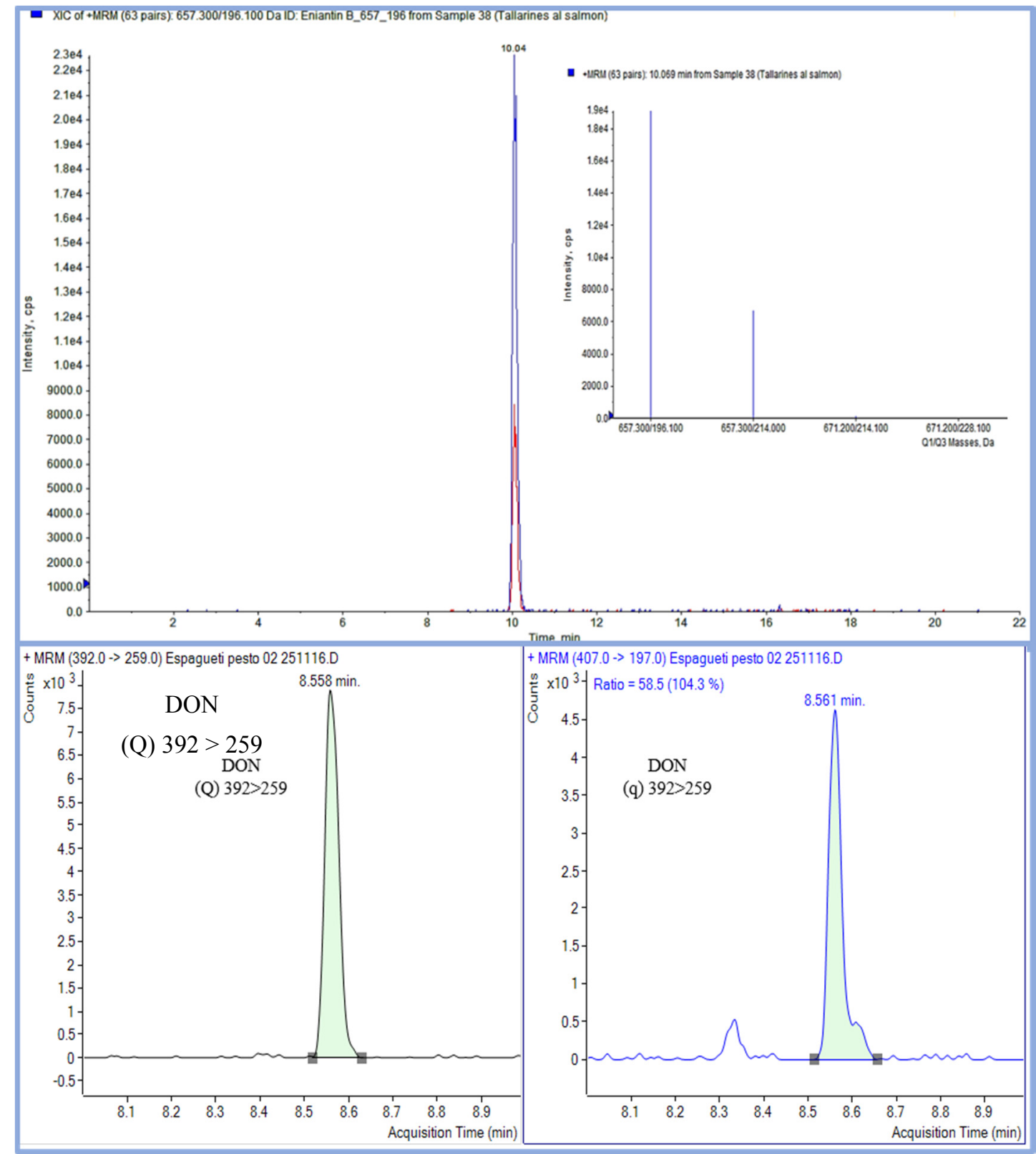

Figure 1. Chromatogram obtained from a sample of ready-to-eat food mainly prepared with cereals and naturally contaminated with (A) ENB content $86.32 \mu \mathrm{g} / \mathrm{kg}$ (LC-MS/MS) and (B) DON content $21.59 \mu \mathrm{g} / \mathrm{kg}$ at Multiple Reaction Monitoring (MRM) mode by (GC-MS/MS).

\subsection{Mycotoxin Occurrence in Ready-to-Eat Food Samples}

The occurrence of the analyzed mycotoxins in the main food groups studied is presented in Table 4 . The samples mainly prepared with cereals showed contamination by DON $(88 \%)$, ENB (63\%), HT-2 $(50 \%)$, and $\mathrm{AFG}_{2}(13 \%)$. The samples prepared mainly with legumes and vegetables showed DON contamination on $17 \%$ and $25 \%$, respectively. 
Table 4. Occurrence, mean, and range (minimum and maximum) of mycotoxins detected in ready-to-eat food samples.

\begin{tabular}{|c|c|c|c|c|c|}
\hline \multirow{2}{*}{ Mycotoxin } & \multirow{2}{*}{ Parameter } & Cereals & Vegetables & Legumes & Total \\
\hline & & $(n=8)$ & $(n=6)$ & $(n=4)$ & $(n=25)$ \\
\hline \multirow{3}{*}{$\mathrm{DON}$} & Occurrence (\%) & $7(88)$ & $1(17)$ & $1(25)$ & $9(36)$ \\
\hline & Mean $\mu \mathrm{g} / \mathrm{kg}$ & 6.36 & 6.19 & 6.98 & 6.51 \\
\hline & Range (min-max) $\mu \mathrm{g} / \mathrm{kg}$ & $2.61-21.59$ & 6.19 & 6.98 & $2.61-21.59$ \\
\hline \multirow{3}{*}{ ENB } & Occurrence (\%) & $5(63)$ & - & - & $5(20)$ \\
\hline & Mean $\mu \mathrm{g} / \mathrm{kg}$ & 26.91 & n.d. & n.d. & 26.91 \\
\hline & Range (min-max) $\mu \mathrm{g} / \mathrm{kg}$ & $9.83-86.32$ & n.d. & n.d. & $9.83-86.32$ \\
\hline \multirow{3}{*}{ HT-2 } & Occurrence (\%) & $4(50)$ & - & - & $4(16)$ \\
\hline & Mean $\mu \mathrm{g} / \mathrm{kg}$ & 17.39 & n.d. & n.d. & 17.39 \\
\hline & Range (min-max) $\mu \mathrm{g} / \mathrm{kg}$ & $9.06-34.43$ & n.d. & n.d. & $9.06-34.43$ \\
\hline \multirow{3}{*}{$\mathrm{AFG}_{2}$} & Occurrence (\%) & $1(13)$ & - & - & $1(4)$ \\
\hline & Mean $\mu \mathrm{g} / \mathrm{kg}$ & 2.84 & n.d. & n.d. & 2.84 \\
\hline & Range (min-max) $\mu \mathrm{g} / \mathrm{kg}$ & 2.84 & n.d. & n.d. & 2.84 \\
\hline
\end{tabular}

n.d.: not detected.

\section{Discussion}

Regarding mycotoxin presence, the contents determined here were comparable with previous research performed in total diet studies (TDS). López et al. [22] reported DON and ENB contents in pasta at concentrations of 8.7 and $35 \mu \mathrm{g} / \mathrm{kg}$, respectively. Yau et al. [23] also detected DON in a range of $29.95-33.11 \mu \mathrm{g} / \mathrm{kg}$ in pasta, while in vegetables, legumes, and meat samples, the amounts were lower than $5.0 \mu \mathrm{g} / \mathrm{kg}$. Raad et al. [24] detected DON contents at levels of $62.50 \mu \mathrm{g} / \mathrm{kg}$ in pasta and cereal products, $121.16 \mu \mathrm{g} / \mathrm{kg}$ in pizza, and $31.25 \mu \mathrm{g} / \mathrm{kg}$ in legumes. Sirot et al. [25] detected also DON average of $132 \mu \mathrm{g} / \mathrm{kg}$ in pasta. The results obtained by Beltrán et al. [26] showed occurrence of DON in $100 \%$ of pasta and cereal products samples with a maximum value of $203 \mu \mathrm{g} / \mathrm{kg}$. The concentration of DON in cereals samples never exceed the EU maximum limits of $750 \mu \mathrm{g} / \mathrm{kg}$ for dry pasta [7].

Concerning HT-2, the maximum concentration detected in pasta reached $34.43 \mu \mathrm{g} / \mathrm{kg}$. Similar amounts were reported by Sirot et al. [25], who quantified HT-2 at levels of $3-10 \mu \mathrm{g} / \mathrm{kg}$. Leblanc et al. [27] also quantified HT-2 in 238 composite samples with an average level of $270 \mu \mathrm{g} / \mathrm{kg}$. There are many factors that predispose food to mycotoxin production, such as temperature and storage/processing conditions [28].

In this study, mycotoxins were not found in ready-to-eat meals based on meat and fish. However, Tolosa et al. [29] reported the presence ENs in fish product samples at levels ranging from 1.3 to $103 \mu \mathrm{g} / \mathrm{kg}$. Sun et al. [30] also suggested that dried seafood could be invaded by mycotoxigenic fungi under improper storage conditions and reported high levels of ZEA in seafood samples $(317.3 \mu \mathrm{g} / \mathrm{kg})$ and OTA $(1.9 \mu \mathrm{g} / \mathrm{kg})$ which were kept for three months at room temperature.

Several studies were carried out on raw food; Cano-Sancho et al. [31] analyzed the presence of mycotoxins in 479 cereal-based food samples and the percentage of DON positive samples in pasta was $73.4 \%$ with mean concentration of $226 \mu \mathrm{g} / \mathrm{kg}$, while HT-2 toxin was present in $10 \%$ of samples with mean concentration of $51 \mu \mathrm{g} / \mathrm{kg}$. Tolosa et al. [32] analyzed 58 samples of different conventional pasta products, the most prevalent mycotoxin was DON $(100 \%)$ with mean content of $96.93 \mu \mathrm{g} / \mathrm{kg}$, while HT-2 toxin and ENB were detected in $90 \%$ of samples at concentrations from 12.46 to $326.17 \mu \mathrm{g} / \mathrm{kg}$, respectively. Other mycotoxins were detected with high incidence like NIV, ZEA, $\mathrm{ENA}_{1}$, while BEA was present in $10 \%$ of analyzed samples.

A recent study conducted by Stanciu et al. [33] did not quantify BEA in 40 pasta samples, while ENB was detected in $11 \%$ of the samples at average levels of $10.4 \mu \mathrm{g} / \mathrm{kg}$ and ENB in $9 \%$ of the samples at an average level $1.9 \mu \mathrm{g} / \mathrm{kg}$. 
Regarding the presence of emerging mycotoxins in rice, Sifou et al. [34] reported the presence of BEA in $75.5 \%$ of samples between 3.8 and $26.3 \mathrm{mg} / \mathrm{kg}$ and ENA in $5.7 \%$ of analyzed samples with maximum concentration of $448 \mathrm{mg} / \mathrm{kg}$. Makun et al. [35] detected $A F s\left(B_{1}, B_{2}, G_{1}, G_{2}\right)$ in $100 \%$ of rice samples at concentration levels ranging between 28 and $372 \mu \mathrm{g} / \mathrm{kg}$ and OTA in $66.7 \%$ of the samples at average level of $141 \mu \mathrm{g} / \mathrm{kg}$. ZEA was also quantified at $53.4 \%$ of the rice samples at an average level $10.6 \mu \mathrm{g} / \mathrm{kg}$, DON in $28 \%$ of the samples at an average level of $18.9 \mu \mathrm{g} / \mathrm{kg}$, and $\mathrm{FB}_{1}$ and $\mathrm{FB}_{2}$ were found in $14.3 \%$ and $4.8 \%$ at concentrations of 0.2 and $6 \mu \mathrm{g} / \mathrm{kg}$, respectively. Sun et al. [36] reported contents of $\mathrm{AFB}_{1}$ in rice and the contents were less than $5 \mu \mathrm{g} / \mathrm{kg}$, while $7 \%$ of samples were detected as exceeding the national maximum residue limit of $10 \mu \mathrm{g} / \mathrm{kg}$.

On the other hand, some authors have investigated the reduction of mycotoxins during food processing (Table 5); Visconti et al. [13] reported the reduction of DON (until 80\%) in pasta by cooking. Cano-Sancho et al. [37] analyzed the transfer of DON from pasta to boiling water, reaching levels of reduction of $75 \%$. Similar values have been reported by Rodriguez-Carrasco et al. [38] who obtained reduction of DON in cooked pasta from $13 \%$ to $58 \%$. Nijs et al. [39] also observed a reduction of DON $(40 \%)$ and ENNs (17-19\%) in pasta samples after cooking. Comparable results on ENB reduction levels after the cooking of pasta were reported in another study conducted by Serrano et al. [40].

Table 5. Mycotoxin reduction by cooking methods.

\begin{tabular}{cccc}
\hline Mycotoxin & Food & Reduction (\%) & Reference \\
\hline DON & Pasta & $67-80$ & {$[13]$} \\
DON & Pasta & $25-75$ & {$[37]$} \\
DON & Pasta & $13-58$ & {$[38]$} \\
DON & Pasta & $40-50$ & {$[39]$} \\
ENB & Pasta & $17-19$ & {$[39]$} \\
ENB & Pasta & $14-65$ & {$[40]$} \\
AFs & Rice & $51-95$ & {$[41]$} \\
AFs & Rice & 24.8 & {$[42]$} \\
AFB1 & Rice & $78-88$ & {$[43]$} \\
\hline
\end{tabular}

Castells et al. [41] investigated AFs reduction in rice samples by extrusion-cooking and reported reduction of aflatoxin contents, which ranged from 51\% to 95\%. Furthermore, Park et al. [43] also reported $\mathrm{AFB}_{1}$ loss (78-88\%) after pressure cooking. Two different cooking methods were used to evaluate AFs reduction and the authors concluded that steaming of rice samples resulted in the highest aflatoxin reduction (24.8\%) [42]. Neither of the methods described reached $100 \%$ aflatoxin reduction which highlighted the stability of mycotoxins and their resistance to the different applied processes.

Nevertheless, data obtained show that mycotoxin levels found on ready-to-eat samples are below those often reported for raw food and support the idea that ready-to-eat meal analysis is a suitable alternative for accurate mycotoxin exposure assessment.

\section{Conclusions}

Chromatographic methods coupled to mass spectrometry in tandem were used for evaluation of twenty-seven mycotoxins in ready-to-eat food samples achieving very low limits of quantification. DON was quantified in $36 \%$, ENB in $20 \%$, HT-2 in $16 \%$, and $\mathrm{AFG}_{2}$ in $4 \%$ of samples, respectively. No mycotoxins were detected in meat and fish dishes. The occurrence of mycotoxins in ready-to-eat food samples was lower than reported on unprocessed cereals, vegetables, and legumes. Exposure assessment from ready-to-eat meals show lowers levels than those obtained from raw food. The evaluation of mycotoxins in ready-to-eat meals offers a reliable tool for risk assessment, since the culinary processes are taken into account. 


\section{Materials and Methods}

\subsection{Chemicals and Reagents}

Solvents (acetonitrile, hexane, and methanol) were supplied by Merck (Darmstadt, Germany). Deionized water $\left(<18, \mathrm{M} \Omega \mathrm{cm}\right.$ resistivity) was obtained in the laboratory using a Milli-QSP ${ }^{\circledR}$ Reagent Water System (Millipore, Beadford, MA, USA).

Ammonium formate (99\%), formic acid ( $\geq 98 \%$ ), anhydrous magnesium sulphate, and sodium chloride were supplied by Sigma Aldrich (Madrid, Spain). Syringe nylon filters $(13 \mathrm{~mm}$ diameter $0.22 \mu \mathrm{m}$ pore size) were obtained from Analysis Vinicos S.L. (Tomelloso, Spain). The derivatization reagent composed of BSA (N,O-bis(trimethylsily) + TMCS (trimthylcholorosilane) + TMSI ( $N$-trimethylsilyimidazole) (3:2:3) was obtained from Supelco (Bellefonte, PA, USA). Sodium dihydrogen phosphate and disodium phosphate, used to prepare phosphate buffer, were acquired from Panreac Quimica S.L.U. (Barcelona, Spain).

\subsection{Standards and Solutions}

The standards of $\mathrm{AFB}_{1}, \mathrm{AFB}_{2}, \mathrm{AFG}_{1}, \mathrm{AFG}_{2}, \mathrm{OTA}, \mathrm{FB}_{1}, \mathrm{FB}_{2}, \mathrm{ENA}, \mathrm{ENA}_{1}, \mathrm{ENB}, \mathrm{ENB}_{1}, \mathrm{BEA}$, STG, ZON, $\alpha$-ZAL, $\beta$-ZAL, $\alpha$-ZOL, $\beta$-ZOL, DON, 3-ADON, $15-A D O N$, DAS, NIV, FUS-X, NEO, T-2, and HT-2 toxins were purchased from Sigma Aldrich. Individual stocks of all analytes were prepared to obtain $20 \mathrm{mg} / \mathrm{L}$ in methanol and multianalyte working solutions of $2 \mathrm{mg} / \mathrm{L}$ were also used by diluting the individual stock solutions. The multianalyte working standard solution was used for standard calibration curves, matrix-matched calibration curves, and recovery assays. All standards were stored in darkness and kept at $-20^{\circ} \mathrm{C}$.

\subsection{Procedures}

\subsubsection{Samples}

The collection of sample criteria was based on the consumption patterns of the Mediterranean diet, which is characterized by a greater consumption of cereals, vegetables, legumes and fish and less significate amount of meat products CIEAM/FAO [44].

A total of 25 ready-to-eat food samples mainly prepared with cereals $(n=8)$, fish $(n=6)$, legumes $(n=5)$, vegetables $(n=4)$, and meat $(n=2)$ were collected from Valencia University restaurant. For the validation step, $50 \mathrm{~g}$ of each black beans, chickpeas, and lentils were cooked and triturated and $2 \mathrm{~g}$ of this legume composite were used for QuEChERS extraction. The same pattern was used for all the studied composites. $2 \mathrm{~g}$ of cereals composite was taken from $50 \mathrm{~g}$ of each bread, pasta, and rice mixture while vegetables composite resulted from $50 \mathrm{~g}$ of each of red pepper, green pepper, onions, potatoes, zucchini, tomato, and eggplant. The meat composite was prepared blending $50 \mathrm{~g}$ of each of beef, pork, chicken, and finally fish composite resulted from mixing $50 \mathrm{~g}$ of each of salmon, perch, and tuna.

Only the edible parts of each food were considered. Seeds and skins were removed from fruit. The inedible part of meat and fish such as bones, thorns, and skin were also removed according to the Commission Regulation EC/401/2006 [45], before analysis performance. All samples were milled with a knife mill (Oster Classic grinder, Valencia, Spain) and the obtained mixture was stored at $-18{ }^{\circ} \mathrm{C}$ until analysis.

\subsubsection{Extraction Procedure}

All samples were triturated and homogenized before their analysis. Briefly, $2 \mathrm{~g}$ of homogeneous sample were weighed and placed into $50 \mathrm{~mL}$ PTFE centrifugal tubes, and then $10 \mathrm{~mL}$ of water containing $2 \%$ of formic acid were added. The tubes were stirred for $30 \mathrm{~min}$ at $250 \mathrm{rpm}$ using a horizontal shaking device (IKA KS260 basic Stirrer, Staufen, Germany). Ten mL of acetonitrile were added into of tube containing soaked sample and vigorously stirred for $30 \mathrm{~min}$ at $250 \mathrm{rpm}$. In the next step, $4 \mathrm{~g} \mathrm{MgSO}_{4}$ and $1 \mathrm{~g} \mathrm{NaCl}$ were added and shaken for $30 \mathrm{~s}$ in vortex and then centrifuged for 
$10 \mathrm{~min}$ at $5{ }^{\circ} \mathrm{C}$ and $5000 \mathrm{rpm}$ using Eppendorf Centrifuge 5810R (Eppendorf, Hamburg, Germany). Then, $2 \mathrm{~mL}$ of acetonitrile extract were added to $0.1 \mathrm{~g}$ of $\mathrm{C} 18$ silica sorbent and $0.3 \mathrm{~g}$ of $\mathrm{MgSO}_{4}$ for purification before centrifugation $(5000 \mathrm{rpm})$ for $10 \mathrm{~min}$. The purified extract was filtered through a syringe nylon filter and transferred into a vial for the LC-MS/MS analysis and for GC-MS/MS analysis the supernatant was collected and evaporated to dryness under a gentle nitrogen flow.

\subsection{GC-MS/MS Analysis}

Before GC-MS/MS analysis, $50 \mu \mathrm{L}$ of BSA + TMCS + TMSI (3:2:3) was added to the dry extract and left $30 \mathrm{~min}$ at room temperature. Then, $200 \mu \mathrm{L}$ of hexane was added, mixed thoroughly on vortex for $30 \mathrm{~s}$, and washed with $1 \mathrm{ml}$ of phosphate buffer $(60 \mathrm{mM}, \mathrm{pH}$ 7) and mixed until the upper layer was clear. Finally, the hexane layer was transferred to an autosampler vial.

Gas chromatographic determination was carried out using a GC system Agilent 7890A coupled with an Agilent 7000A triple quadruple mass spectrometer with inter electron-impact ion source (EI, 70 Ev) and Agilent 7693 auto sampler (Agilent Technologies, Palo Alto, CA, USA). Quantitation data were acquired at selection reaction monitoring (SRM). The transfer line and source temperatures were $280^{\circ}$ and $230^{\circ}$, respectively. The collision gas for MS/MS experiments was nitrogen, and the helium was used as quenching gas, both at $99.999 \%$ purity supplied by Carburos Metálicos S.L. (Barcelona, Spain). Analytes were separated on a HP-5MS $30 \mathrm{~m} \times 0.25 \mathrm{~mm} \times 0.25 \mu \mathrm{m}$ capillary column. One microliter of the final clean extract of mycotoxins was injected in splitless mode in program able temperature vaporization (PTV) inlet at $250^{\circ} \mathrm{C}$, employing helium as the carried gas at fixed pressure of $20.3 \mathrm{psi}$. The oven temperature started at $80^{\circ} \mathrm{C}$ and increased to $245^{\circ} \mathrm{C}$ at $60^{\circ} \mathrm{C} / \mathrm{min}$, held there for $3 \mathrm{~min}$, and then increased to $260^{\circ} \mathrm{C}$ progressively at $3{ }^{\circ} \mathrm{C} / \mathrm{min}$ and finally to $270{ }^{\circ} \mathrm{C}$ at $10^{\circ} \mathrm{C} / \mathrm{min}$ and then held for $10 \mathrm{~min}$. Data were acquired and processed using Agilent Masshunter version B.04.00 software (Agilent Technologies, Palo Alto, CA, USA, 2015).

\subsection{LC-MS/MS Analysis}

LC-MS/MS analyses were conducted on a system consisting of an Agilent 1200 chromatographic system (Agilent Technologies, Palo Alto, CA, USA) coupled to a 3200 QTRAP ${ }^{\circledR}$ mass spectrometer (AB SCIEX, Foster City, CA, USA) equipped with a turbo electrospray ionization (ESI) interface. Separation of analyte was performed using a Gemini-NX LC-column (Phenomenex, Aschaffenburg, Germany) $(150 \mathrm{~mm} \times 4.6 \mathrm{~mm}, 5 \mu \mathrm{m}$ of particle size) preceded by a guard column. The flow rate was set to $0.8 \mathrm{~mL}$ $\min ^{-1}$, and the oven temperature was $40^{\circ} \mathrm{C}$. The two elution mobile phases were made up of the water slightly acidified with $5 \mathrm{mM}$ ammonium formate and $0.1 \%$ formic acid (mobile phase A) and methanol acidified with $5 \mathrm{mM}$ ammonium formate $0.1 \%$ formic acid (mobile phase B). The elution gradient started with $0 \%$ of eluent B, increased to $100 \%$ in $10 \mathrm{~min}$, decreased to $80 \%$ in $5 \mathrm{~min}$ and, finally, decreased to $100 \%$ in $10 \mathrm{~min}$, decreased to $80 \%$ in $5 \mathrm{~min}$ and, finally, decreased to $70 \%$ in $2 \mathrm{~min}$. The column was, readjusted to the initial conditions and equilibrated for $7 \mathrm{~min}$. The volume of the injections was $20 \mu \mathrm{L}$.

The analysis was performed using the Turbo Ion Spray instrument in positive ionization mode (ESI+). Nitrogen served as the nebulizer and collision gas. The operating conditions for the analysis were the following: ion spray voltage, $5500 \mathrm{~V}$; curtain gas, 20 (arbitrary units); GS1 and GS2, 50 and $50 \mathrm{psi}$, respectively and probe temperature (TEM), $450{ }^{\circ} \mathrm{C}$.

\subsection{Method Validation}

The method was validated for linearity, accuracy, repeatability (intraday and interday), following the EU Commission Decision 2002/657/EC [21], with food mixture of cereals, fish, legume, vegetable, and meat samples. In order to determine the linearity, calibration curves for each studied mycotoxin were constructed from standards and from extract of blank samples of cereals, fish, legume, vegetables, and meat previously analyzed and did not contain any studied compound. Linear range was tested at eight concentration levels from 0.15 to $200 \mu \mathrm{g} / \mathrm{kg}$. Matrix-matched calibration curves were built by 
spiking blank samples with select mycotoxins after the extraction process. Both external calibration curves and matrix-matched calibration curves were constructed by plotting peak areas against concentration and linear functions were applied to the calibration curves. Matrix effect (ME) was assessed for each analyte by comparing the slope of the standard calibration curve (slope with standard)

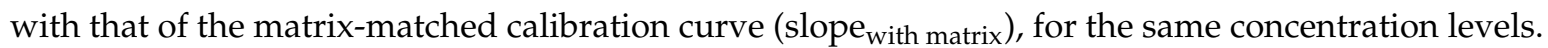

Sensitivity was evaluated by limit of detection (LOD) and limit of quantification (LOQ), which were estimated for a signal-to-noise ratio $(S / N) \geq 3$ and $\geq 10$, respectively, from chromatograms of samples spiked at the lowest level validated. LODs were estimated using an extract of a blank of the different matrix (previous analyzed and negative for the mycotoxin included in this study), fortified with decreasing concentrations of the analytes, where the response of the qualifier ion was at least 3 times the response of the blank extract $(n=9)$. The LOQs were estimated in the same way as the LODs, but using criterion of $\mathrm{S} / \mathrm{N} \geq 10$ for the qualifier ion.

Accuracy was evaluated through recovery studies and was determined calculating the ratio of the peak areas for each mycotoxin by analyzing the samples spiked before and after extraction at three addition levels 25, 50, and $100 \mu \mathrm{g} / \mathrm{kg}$ for all mycotoxins analyzed $\left(\mathrm{AFB}_{1}, \mathrm{AFB}_{2}, \mathrm{AFG}_{1}, \mathrm{AFG}_{2}, \mathrm{OTA}\right.$, $\mathrm{FB}_{1}, \mathrm{FB}_{2}$, ENA, ENA 1 , ENB, ENB 1 , BEA, STG, ZON, $\alpha$-ZAL, $\beta$-ZAL, $\alpha$-ZOL, $\beta$-ZOL, DON, 3-ADON, 15-ADON, DAS, NIV, FUS-X, NEO, T-2, and HT-2 toxins). Intra-day precision and inter-day precision (repeatability) were also investigated.

The precision of the method was determined by repeatability $(n=3)$ and reproducibility $(n=9)$ studies, and expressed as the relative standard deviation (RSD, \%). The intra-day precision was expressed as the standard deviation of the recovery values of the spiked samples measured during the same day $(n=3)$. The inter-day precision was determined by analyzing the spiked samples for three different days $(n=9)$.

Author Contributions: G.F. conceived the experiment; H.B. and E.F. designed the experiments; D.C. performed the experiments and wrote the manuscript. All authors read and approved the final form of the manuscript.

Acknowledgments: This research was supported by the Spanish Ministry of Economy and Competitiveness (AGL2016-77610-R) and Government Scholarship program "Carlos Antonio López-Paraguay".

Conflicts of Interest: The authors declare no conflict of interest and informed consent was obtained from all individual participants included in the study.

\section{References}

1. Yang, J.; Li, J.; Jiang, Y.; Duan, X.; Qu, H.; Yang, B.; Sivakumar, D. Natural occurrence, analysis, and prevention of mycotoxins in fruits and their processed products. Crit. Rev. Food Sci. Nutr. 2014, 54, 64-83. [CrossRef] [PubMed]

2. Alshannaq, A.; Yu, J.H. Occurrence, toxicity, and analysis of major mycotoxins in food. Int. J. Environ. Res. Public Health 2017, 14, 632. [CrossRef] [PubMed]

3. Juan-García, A.; Manyes, L.; Ruiz, M.J.; Font, G. Applications of flow cytometry to toxicological mycotoxin effects in cultured mammalian cells: A review. Food Chem. Toxicol. 2013, 56, 40-59. [CrossRef] [PubMed]

4. Marin, S.; Ramos, A.J.; Cano-Sancho, G.; Sanchis, V. Mycotoxins: Occurrence, toxicology, and exposure assessment. Food Chem. Toxicol. 2013, 60, 218-237. [CrossRef] [PubMed]

5. Prosperini, A.; Berrada, H.; Ruiz, M.J.; Caloni, F.; Coccini, T.; Spicer, L.J.; Perego, M.C.; Lafranconi, A. A Review of the Mycotoxin enniatin B. Front. Public Health 2017, 5, 304. [CrossRef] [PubMed]

6. Prosperini, A.; Meca, G.; Font, G.; Ruiz, M.J. Study of the cytotoxic activity of beauvericin and fusaproliferin and bioavailability in vitro on Caco-2 cells. Food Chem. Toxicol. 2012, 50, 2356-2361. [CrossRef] [PubMed]

7. European Commission. Commission Regulation (EC) No 1881/2006 of 19 December 2006 setting maximum levels for certain contaminants in foodstuffs. Off. J. Eur. Union 2006, L364, 5-24.

8. Juan, C.; Covarelli, L.; Beccari, G.; Colasante, V.; Mañes, J. Simultaneous analysis of twenty-six mycotoxins in durum wheat grain from Italy. Food Control 2016, 62, 322-329. [CrossRef] 
9. García-Moraleja, A.; Font, G.; Mañes, J.; Ferrer, E. Development of a new method for the simultaneous determination of 21 mycotoxins in coffee beverages by liquid chromatography tandem mass spectrometry. Food Res. Int. 2015, 72, 247-255. [CrossRef]

10. Rodríguez-Carrasco, Y.; Mañes, J.; Berrada, H.; Juan, C. Development and Validation of a LC-ESI-MS/MS Method for the Determination of Alternaria Toxins Alternariol, Alternariol Methyl-Ether and Tentoxin in Tomato and Tomato-Based Products. Toxins 2016, 8, 328. [CrossRef] [PubMed]

11. Danezis, G.P.; Anagnostopoulos, C.J.; Liapis, K.; Koupparis, M.A. Multi-residue analysis of pesticides, plant hormones, veterinary drugs and mycotoxins using HILIC chromatography-MS/MS in various food matrices. Anal. Chim. Acta 2016, 942, 121-138. [CrossRef] [PubMed]

12. Milani, J.; Maleki, G. Effects of processing on mycotoxin stability in cereals. J. Sci. Food Agric. 2014, 94, 2372-2375. [CrossRef] [PubMed]

13. Visconti, A.; Haidukowski, E.M.; Pascale, M.; Silvestri, M. Reduction of deoxynivalenol during durum wheat processing and spaghetti cooking. Toxicol. Lett. 2004, 153, 181-189. [CrossRef] [PubMed]

14. Serrano, A.B.; Font, G.; Mañes, J.; Ferrer, E. Effects of technological processes on enniatin levels in pasta. J. Sci. Food Agric. 2016, 96, 1756-1763. [CrossRef] [PubMed]

15. Sakuma, H.; Watanabe, Y.; Furusawa, H.; Yoshinari, T.; Akashi, H.; Kawakami, H.; Saito, S.; Sugita-Konishi, Y. Estimated dietary exposure to mycotoxins after taking into account the cooking of staple foods in Japan. Toxins 2013, 5, 1032-1042. [CrossRef] [PubMed]

16. EFSA Panel on Contaminants in the Food Chain. Scientific Opinion on the risks to human and animal health related to the presence of beauvericin and enniatins in food and feed. EFSA J. 2014, 12, 3802.

17. Saladino, F.; Quiles, J.M.; Mañes, J.; Fernández-Franzón, M.; Luciano, F.B.; Meca, G. Dietary exposure to mycotoxins through the consumption of commercial bread loaf in Valencia, Spain. LWT-Food Sci. Technol. 2017, 75, 697-701. [CrossRef]

18. Juan, C.; Berrada, H.; Mañes, J.; Oueslati, S. Multi-mycotoxin determination in barley and derived products from Tunisia and estimation of their dietary intake. Food Chem. Toxicol. 2017, 103, 148-156. [CrossRef] [PubMed]

19. Anastassiades, M.; Maštovská, K.; Lehotay, S.J. Evaluation of analyte protectants to improve gas chromatographic analysis of pesticides. J. Chromatogr. A 2003, 1015, 163-184. [CrossRef]

20. Pereira, V.L.; Fernandes, J.O.; Cunha, S.C. Comparative assessment of three cleanup procedures after QuEChERS extraction for determination of trichothecenes (type A and type B) in processed cereal-based baby foods by GC-MS. Food Chem. 2015, 182, 143-149. [CrossRef] [PubMed]

21. European Commission. Commission Decision (EC) No 657/2002 of 12 August 2002 concerning the performance of analytical methods and the interpretation of results. Off. J. Eur. Union 2002, L221, 8-36.

22. López, P.; De Rijk, T.; Sprong, R.C.; Mengelers, M.J.B.; Castenmiller, J.J.M.; Alewijn, M. A mycotoxin-dedicated total diet study in The Netherlands in 2013: Part II-Occurrence. World Mycotoxin J. 2016, 9, 89-108. [CrossRef]

23. Yau, A.T.C.; Chen, M.Y.Y.; Lam, C.H.; Ho, Y.Y.; Xiao, Y.; Chung, S.W.C. Dietary exposure to mycotoxins of the Hong Kong adult population from a Total Diet Study. Food Addit. Contam. Part A 2016, 33, 1026-1035. [CrossRef] [PubMed]

24. Raad, F.; Nasreddine, L.; Hilan, C.; Bartosik, M.; Parent-Massin, D. Dietary exposure to aflatoxins, ochratoxin A and deoxynivalenol from a total diet study in an adult urban Lebanese population. Food Chem. Toxicol. 2014, 73, 35-43. [CrossRef] [PubMed]

25. Sirot, V.; Fremy, J.; Leblanc, J. Dietary exposure to mycotoxins and health risk assessment in the second french total diet study. Food Chem. Toxicol. 2013, 52, 1-11. [CrossRef] [PubMed]

26. Beltrán, E.; Ibáñez, M.; Portolés, T.; Ripollés, C.; Sancho, J.V.; Yusà, V.; Marin, S.; Hernández, F. Development of sensitive and rapid analytical methodology for food analysis of 18 mycotoxins included in a total diet study. Anal. Chim. Acta 2013, 783, 39-48. [CrossRef] [PubMed]

27. Leblanc, J.C.; Tard, A.; Volatier, J.L.; Verger, P. Estimated dietary exposure to principal food mycotoxins from the first French Total Diet Study. Food Addit. Contam. 2005, 22, 652-672. [CrossRef] [PubMed]

28. Covarelli, L.; Beccari, G.; Prodi, A.; Generotti, S.; Etruschi, F.; Juan, C.; Ferrer, E.; Mañes, J. Fusarium species, chemotype characterisation and trichothecene contamination of durum and soft wheat in an area of central Italy. J. Sci. Food Agric. 2015, 95, 540-551. [CrossRef] [PubMed] 
29. Tolosa, J.; Font, G.; Mañes, J.; Ferrer, E. Mitigation of enniatins in edible fish tissues by thermal processes and identification of degradation products. Food Chem. Toxicol. 2017, 101, 67-74. [CrossRef] [PubMed]

30. Sun, W.; Han, Z.; Aerts, J.; Nie, D.; Jin, M.; Shi, W.; Zhao, Z.; De Saeger, S.; Zhao, Y.; Wu, A. A reliable liquid chromatography-tandem mass spectrometry method for simultaneous determination of multiple mycotoxins in fresh fish and dried seafoods. J. Chromatogr. A 2015, 1387, 42-48. [CrossRef] [PubMed]

31. Cano-Sancho, G.; Valle-Algarra, F.M.; Jiménez, M.; Burdaspal, P.; Legarda, T.M.; Ramos, A.J.; Sanchis, V.; Marín, S. Presence of trichothecenes and co-occurrence in cereal-based food from Catalonia (Spain). Food Control 2011, 22, 490-495. [CrossRef]

32. Tolosa, J.; Graziani, G.; Gaspari, A.; Chianese, D.; Ferrer, E.; Mañes, J.; Ritieni, A. Multi-Mycotoxin Analysis in Durum Wheat Pasta by Liquid Chromatography Coupled to Quadrupole Orbitrap Mass Spectrometry. Toxins 2017, 9, 59. [CrossRef] [PubMed]

33. Stanciu, O.; Juan, C.; Miere, D.; Loghin, F.; Mañes, J. Presence of Enniatins and Beauvericin in Romanian Wheat Samples: From Raw Material to Products for Direct Human Consumption. Toxins 2017, 9, 189. [CrossRef] [PubMed]

34. Sifou, A.; Meca, G.; Serrano, A.B.; Mahnine, N.; El Abidi, A.; Mañes, J.; El Azzouzi, M.; Zinedine, A. First report on the presence of emerging Fusarium mycotoxins enniatins $\left(A, A_{1}, B, B_{1}\right)$, beauvericin and fusaproliferin in rice on the Moroccan retail markets. Food Control 2011, 22, 1826-1830. [CrossRef]

35. Makun, H.A.; Dutton, M.F.; Njobeh, P.B.; Mwanza, M.; Kabiru, A.Y. Natural multi-occurrence of mycotoxins in rice from Niger State, Nigeria. Mycotoxin Res. 2011, 27, 97-104. [CrossRef] [PubMed]

36. Sun, X.D.; Su, P.; Shan, H. Mycotoxin Contamination of Rice in China. J. Food Sci. 2017, 82, 573-584. [CrossRef] [PubMed]

37. Cano-Sancho, G.; Sanchis, V.; Ramos, A.J.; Marín, S. Effect of food processing on exposure assessment studies with mycotoxins. Food Addit. Contam. Part A 2013, 30, 867-875. [CrossRef] [PubMed]

38. Rodríguez-Carrasco, Y.; Mañes, J.; Berrada, H.; Font, G. Preliminary estimation of deoxynivalenol excretion through a $24 \mathrm{~h}$ pilot study. Toxins 2015, 7, 705-718. [CrossRef] [PubMed]

39. Nijs, M.; van den Top, H.; de Stoppelaar, J.; Lopez, P.; Mol, H. Fate of enniatins and deoxynivalenol during pasta cooking. Food Chem. 2016, 213, 763-767. [CrossRef] [PubMed]

40. Serrano, A.B.; Font, G.; Mañes, J.; Ferrer, E. Development a mitigation strategy of enniatins in pasta under home-cooking conditions. LWT-Food Sci. Technol. 2016, 65, 1017-1024. [CrossRef]

41. Castells, M.; Marín, S.; Sanchis, V.; Ramos, A.J. Reduction of Aflatoxins by Extrusion-Cooking of Rice Meal. J. Food Sci. 2006, 71, 369-377. [CrossRef]

42. Sani, A.M.; Azizi, E.G.; Salehi, E.A.; Rahimi, K. Reduction of aflatoxin in rice by different cooking methods. Toxicol. Ind. Health 2014, 30, 546-550. [CrossRef] [PubMed]

43. Park, J.W.; Kim, Y.B. Effect of pressure cooking on aflatoxin $B_{1}$ in rice. J. Agric. Food Chem. 2006, 54, $2431-2435$. [CrossRef] [PubMed]

44. CIHEAM/FAO Centre International de Hautes Agronomiques Méditerranéennes/Food and Agriculture Organization of the United Nations. Mediterranean Food Consumption Patterns: Diet, Environment, Society, Economy and Health. A White Paper Priority 5 of Feeding Knowledge Programme, Expo Milan 2015. Available online: http:/ / www.fao.org/3/a-i4358e.pdf (accessed on 10 February 2017).

45. European Commission. Commission Regulation (EC) No 401/2006 of 23 February 2006 laying down the methods of sampling and analysis for the official control of the levels of mycotoxins in foodstuffs. Off. J. Eur. Union 2006, L70, 12-34.

(C) 2018 by the authors. Licensee MDPI, Basel, Switzerland. This article is an open access article distributed under the terms and conditions of the Creative Commons Attribution (CC BY) license (http:// creativecommons.org/licenses/by/4.0/). 